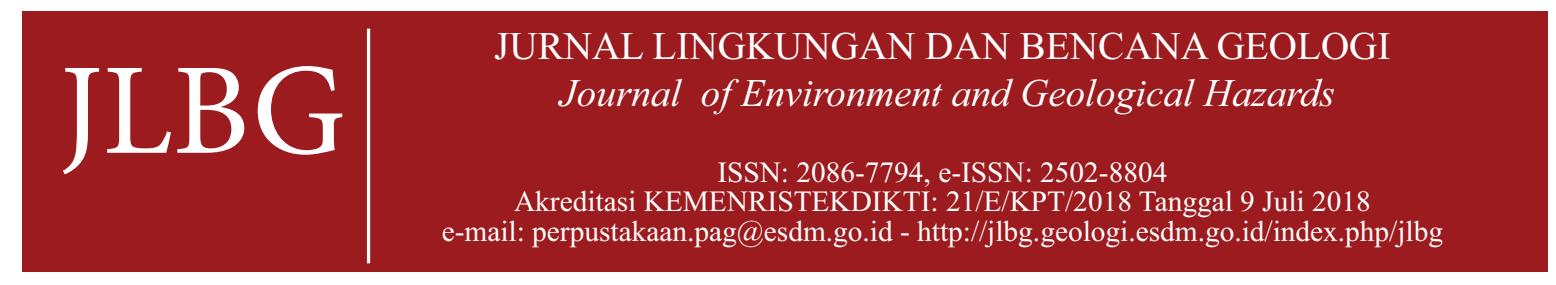

\title{
Prediksi Tipe Longsor di Desa Clapar \\ Menggunakan Metode Geolistrik Resistivitas Konfigurasi Dipol-dipol
}

\author{
Prediction of the Landslides Type in Clapar Village \\ Using Geoelectrical Resistivity Method of Dipole-dipole Configuration
}

\author{
Muhardi $^{1}$ dan Wahyudi² \\ ${ }^{1}$ Program Studi Geofisika, FMIPA, Universitas Tanjungpura, Pontianak \\ Jl. Prof. Hadari Nawawi, Pontianak Tenggara, Bansir Laut, Kec. Pontianak Tenggara, \\ Kota Pontianak, Kalimantan Barat 78115 Indonesia \\ ${ }^{2}$ Program Studi Geofisika, FMIPA, Universitas Gadjah Mada, \\ Bulaksumur, Caturtunggal, Kec. Depok, Kabupaten Sleman, Daerah Istimewa Yogyakarta 55281 Indonesia \\ e-mail: muhardi@physics.untan.ac.id \\ Naskah diterima 20 September 2019, selesai direvisi 29 Agustus 2020, dan disetujui 30 Agustus 2020
}

\begin{abstract}
ABSTRAK
Desa Clapar merupakan salah satu desa di Kabupaten Banjarnegara, Jawa Tengah, yang tergolong daerah rawan longsor. Tujuan penelitian ini adalah untuk memprediksi tipe longsor dengan menganalisis bidang gelincir berdasarkan sebaran nilai resistivitas secara lateral. Penelitian ini mengaplikasikan metode geolistrik resistivitas dengan konfigurasi dipol-dipol. Pengukuran dilakukan di dua lokasi, yaitu lereng bukit sebelah barat dan timur kawasan pemukiman, yang masing-masing terdiri dari 2 dan 3 lintasan pengukuran. Hasil penelitian menunjukkan bahwa bidang gelincir pada lokasi pertama mempunyai nilai resistivitas sebesar 2,93 - 47,43 $\Omega \mathrm{m}$, berupa lapisan lempung dengan bidang berbentuk relatif rata pada kedalaman 4,5 - 15,0 meter. Demikian juga dengan bidang gelincir pada lokasi kedua yang mempunyai nilai resistivitas sebesar 1,32 - 14,38 $\Omega \mathrm{m}$, berupa lapisan lempung dengan bidang berbentuk relatif rata pada kedalaman 1,5 - 7,0 meter. Hasil penelitian juga menunjukkan bahwa tipe longsor di Desa Clapar diprediksi sebagai longsor translasi.
\end{abstract}

Kata kunci: bidang gelincir, Clapar, konfigurasi dipol-dipol, metode geolistrik resistivitas, tipe longsor

\section{ABSTRACT}

Clapar Village is one of the village in Banjarnegara Regency, Central Java, which is classified as landslides prone area. This study aims to predict the landslides type by analyzing the slip surface based on the distribution of resistivity values laterally. This study applied the geoelectrical resistivity method of dipole-dipole configuration. The measurements were conducted in twoareas, on the hill slope western and eastern of the settlement area, which was consist of 2 and 3 lines, respectively. Thestudy results show that the slide surface in the first area has resistivity value of 2.93 - 47.43 Sm inferred as relatively flat clay layer at a depth of $4.5-15.0$ meters. While The slip surfacein the second area has a similar case with resistivity value of $1.32-14.38 \Omega \mathrm{m}$ inferred as a clay layer at a depth of $1.5-7.0 \mathrm{~m}$. In addition, the landslides type in Clapar Village is predicted as a translational landslides.

Keywords: slip surface, Clapar, dipole-dipole configuration, geoelectrical resistivity method, landslides type

\section{PENDAHULUAN}

Kabupaten Banjarnegara merupakan daerah dengan topografi perbukitan hingga pegunungan. Kondisi morfologi yang bergelombang dengan curah hujan yang cukup tinggi, menyebabkan kabupaten ini merupakan daerah yang rawan terhadap terhadap bencana longsor (Paripurno drr, 2019). Kawasan lembah 
Sungai Serayu yang membentuk suatu dataran merupakan daerah yang relatif stabil terhadap gerakan tanah, sedangkan pada daerah Pegunungan Serayu Utara dan Pegunungan Serayu Selatan merupakan daerah-daerah yang labil terhadap gerakan tanah, sehingga mempunyai tingkat kerentanan yang cukup tinggi karena dikontrol oleh topografi yang relatif curam. Permata drr., (2016) menyatakan bahwa kondisi topografi yang cukup curam dan intensitas curah hujan yang relatif tinggi menjadi faktor utama yang menyebabkan terjadinya longsor di Banjarnegara.

Bencana longsor di Desa Clapar terjadi pada 2016 dan 2017, seperti yang diperlihatkan pada Gambar 1. Lereng perbukitan Desa Clapar memiliki tingkat kemiringan yang cukup tinggi dan sebagian besar dijadikan area perkebunan sehingga mengurangi stabilitas lereng, akibatnya jika terjadi curah hujan yang cukup tinggi, lereng perbukitan ini berisiko mengalami longsor. Hidayat dan Munir (2019) menyatakan bahwa stabilitas lereng dipengaruhi oleh jenis material, kemiringan, dan hujan. Material yang tidak kompak akan mudah mengalami longsor bila mengalami infiltrasi air.

Kerugian yang dialami oleh pemerintah dan masyarakat di Desa Clapar berupa rusaknya fasilitas umum dan perumahan, disebabkan belum maksimalnya upaya mitigasi bencana berupa pemetaan area rawan longsor. Hingga saat ini area yang berpotensi longsor tersebut masih tetap dijadikan tempat pemukiman warga setempat.

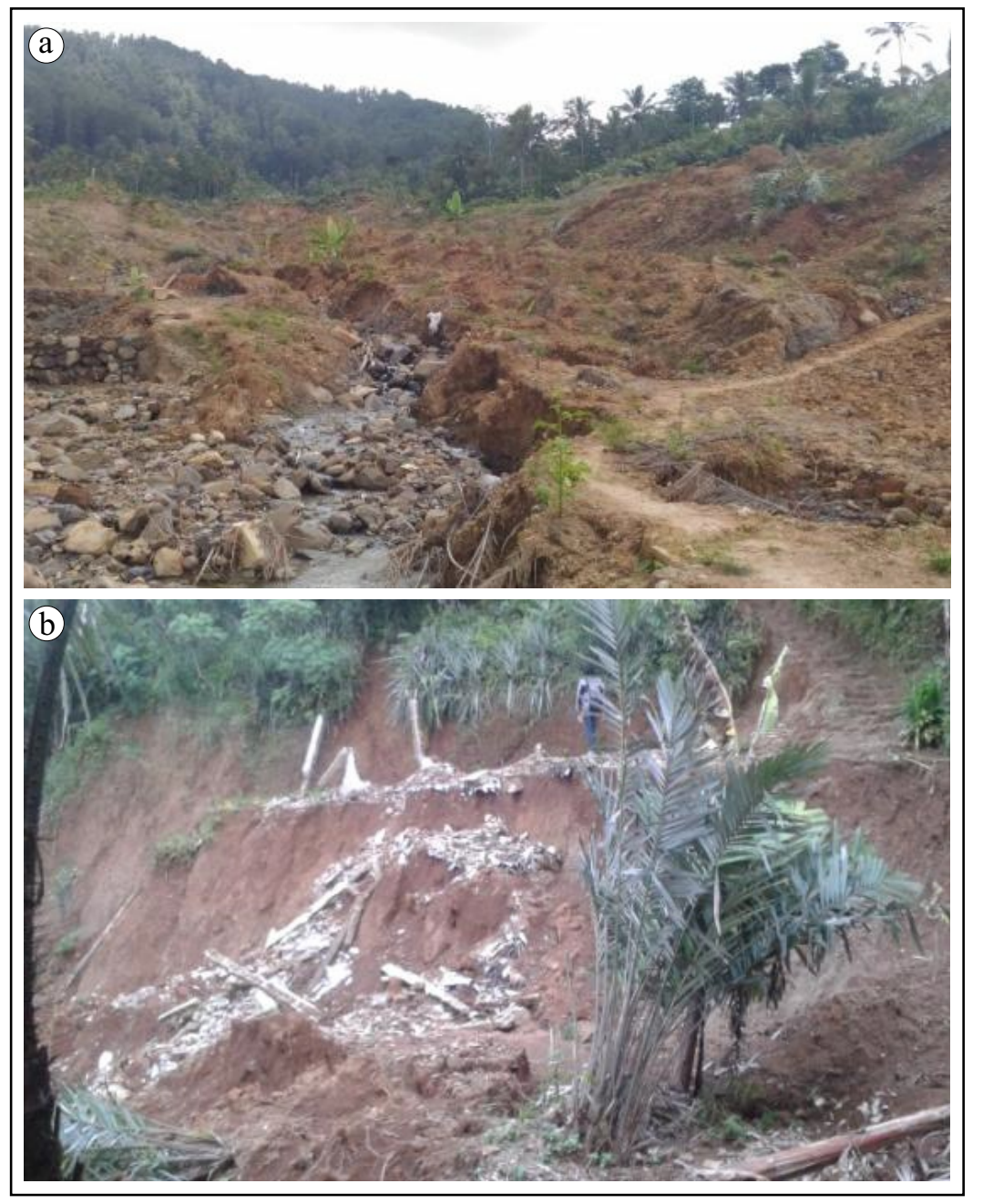

Gambar 1. Area yang telah mengalami longsor di Desa Clapar; (a) Tahun 2016, dan (b) Tahun 2017. 
Tipe longsor sangat dipengaruhi oleh faktor pengontrol berupa bidang gelincir. Metode geolistrik merupakan metode yang sering digunakan untuk meneliti longsor (Ling drr., 2016), juga efektif untuk meneliti longsor batuan, tanah, maupun endapan lempung, namun tidak efektif untuk meneliti longsor runtuhan (Bell drr., 2006).

Longsor merupakan gerakan ke bawah dari material pembentuk lereng yang terdiri dari batuan dan tanah alami maupun buatan, atau kombinasi dari bahan-bahan tersebut. Material longsor dapat bergerak dalam beberapa cara diantaranya yaitu jatuhan (fall), robohan (topple), longsoran (slide), sebaran (spread), aliran (flow) atau dengan kombinasinya (Hardiatmo, 2012). Gaya gravitasi merupakan faktor pendorong utama disamping adanya faktor pemicu berupa adanya gerakan air (Sidle dan Ochiai, 2006). Longsor dapat terjadi pada bidang gelincir (Sutasoma drr., 2017) baik yang permukaannya melengkung sehingga dapat menyebabkan longsor dengan tipe rotasi maupun yang permukaan- nya rata (bergelombang landai) sehingga dapat menyebabkan longsor dengan tipe translasi (Highland dan Browbrsky, 2008).

\section{METODE PENELITIAN}

Penelitian dilakukan di dua lokasi. Lokasi pertama berada pada lereng perbukitan di sebelah barat pemukiman dengan dua lintasan pengukuran (lintasan 1 dan 2), sedangkan lokasi kedua berada di sebelah timur pemukiman dengan tiga lintasan pengukuran (lintasan 3, 4, dan 5). Kedua lokasi ini dipilih karena merupakan area yang diprediksi berpotensi mengalami longsor berikutnya, sedangkan area yang telah mengalami longsor sebelumnya tidak dimungkinkan untuk dilakukan akuisisi karena kondisi tanah yang masih belum stabil. Adapun desain penelitian geolistrik di Desa Clapar dapat dilihat pada Gambar 2.

Distribusi nilai resistivitas secara lateral akan menghasilkan penampang resistivitas dua dimensi. Penampang resistivitas ini kemudian

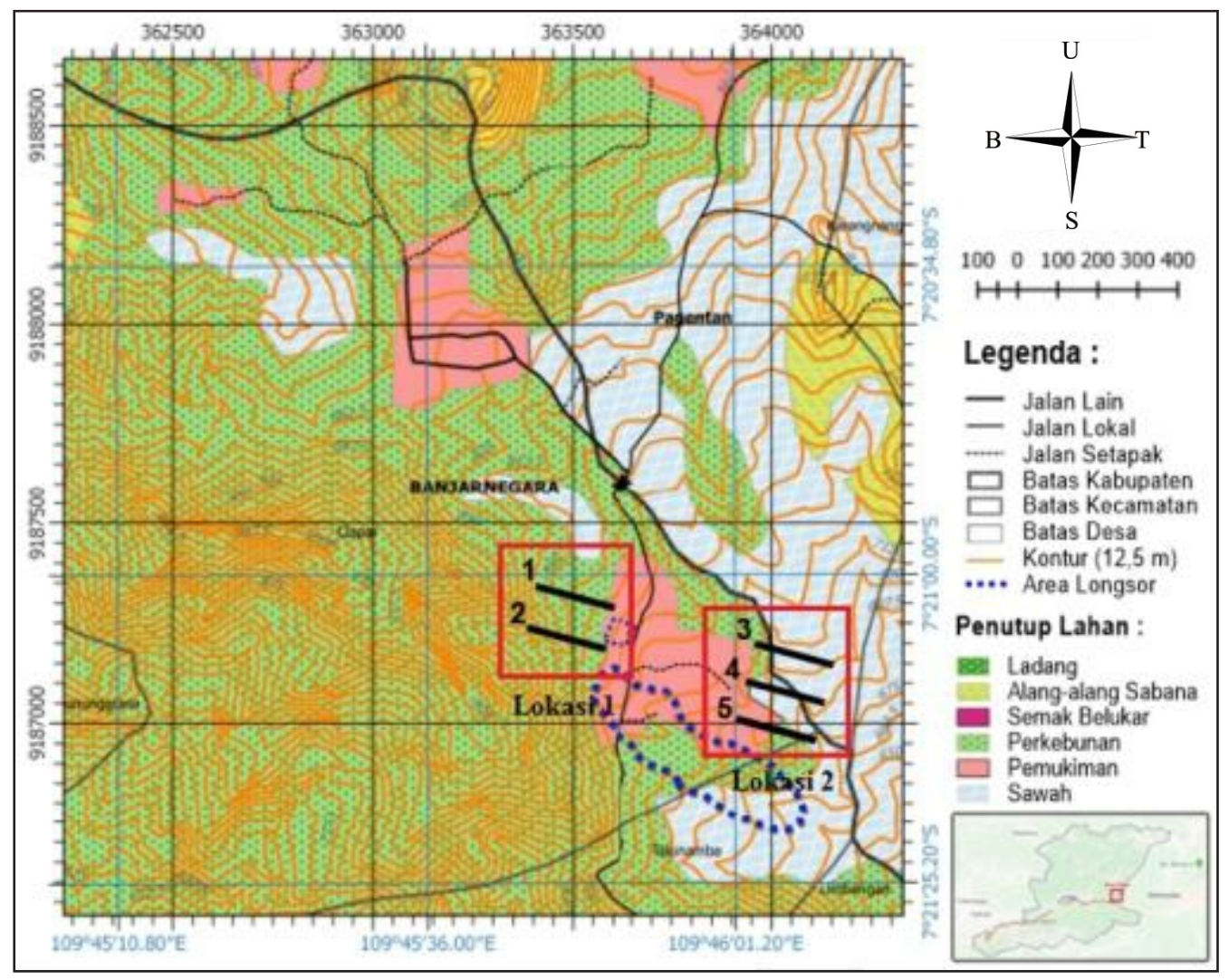

Gambar 2. Desain penelitian geolistrik di Desa Clapar. 
dijadikan dasar dalam menggambarkan permukaan bidang gelincir, sedangkan permukaan bidang gelincir digunakan untuk mengidentifikasi tipe longsor di daerah penelitian. Secara umum proses penelitian dapat dilihat pada Gambar 3 .

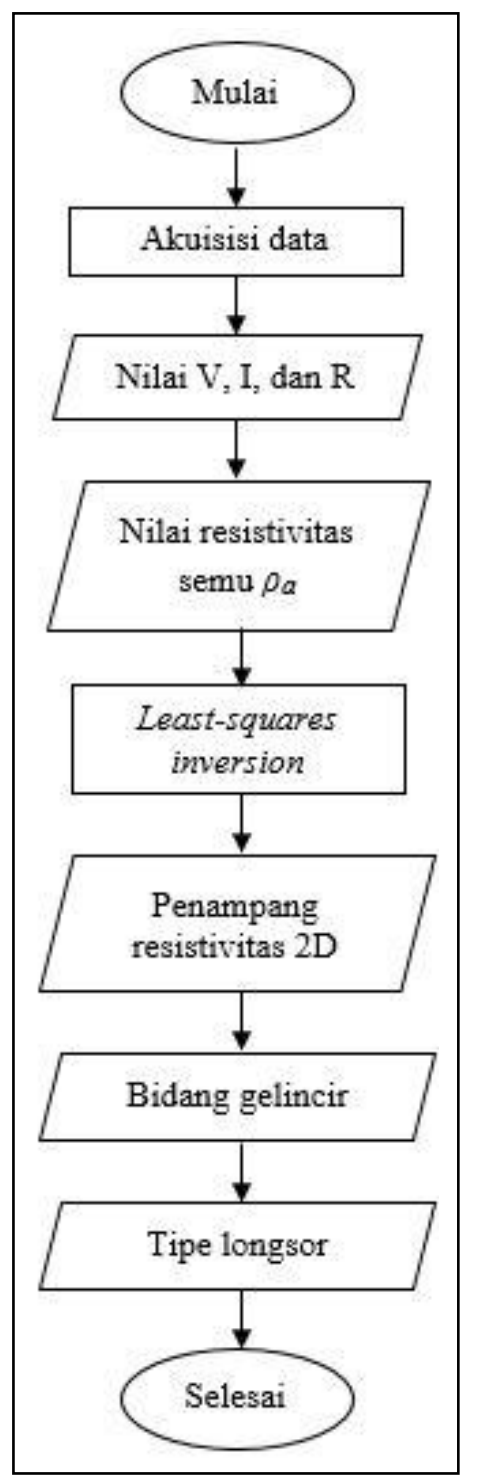

Gambar 3. Diagram alir penelitian.

Metode geolistrik memanfaatkan nilai resistivitas pada material longsor dan bidang gelincir yang umumnya mempunyai litologi yang berbeda. Nilai resistivitas pada material longsor dan bidang gelincir ini dimanfaatkan untuk mendeskripsikan litologi dan sifat-sifat lapisan bawah permukaan yang mengacu pada nilai resistivitas secara teoritis seperti pada Tabel 1 .
Tabel 1. Klasifikasi tingkat keasinan air tanah (PAHIAA Jakarta, 1986 dalam Prayogi drr., 2018).

\begin{tabular}{|ll|}
\hline Material & Resistivitas $(\mathbf{\Omega m})$ \\
\hline Kuarsa & $3 \times 10^{2}-10^{6}$ \\
Granit & $3 \times 10^{2}-3 \times 10^{6}$ \\
Diorit & $10^{4}-10^{5}$ \\
Basal & $10-1,3 \times 10^{7}$ \\
Sekis (grafit) & $10-10^{2}$ \\
Serpih terkonsolidasi & $20-2 \times 10^{3}$ \\
Konglomerat & $2 \times 103-104$ \\
Batupasir & $1-7,4 \times 10^{8}$ \\
Batugamping & $5 \times 10-107$ \\
Lempung & $1-100$ \\
Tanah (40\% lempung) & 8 \\
Tanah (20\% lempung) & 33 \\
Tanah penutup & $250-1,700$ \\
Lempung (kering) & $50-150$ \\
Tanah berpasir kering & $120-750$ \\
Lempung berpasir & $80-1,050$ \\
\hline
\end{tabular}

Marwanta (2017) menyatakan bahwa interpretasi harus diperkuat dengan memperhatikan kondisi geologi dan singkapan batuan di lapangan.

Metode geolistrik dilakukan dengan menginjeksikan arus listrik ke bawah permukaan dengan menggunakan elektroda arus, kemudian mengukur nilai beda potensial dengan elektroda potensial yang dipasang di permukaan. Pada prinsipnya arus listrik yang diinjeksikan akan menyebar melewati lapisan bawah permukaan, sehingga mengakibatkan adanya beda potensial yang nilainya dipengaruhi oleh resistivitas dari lapisan tersebut (Gambar 4).

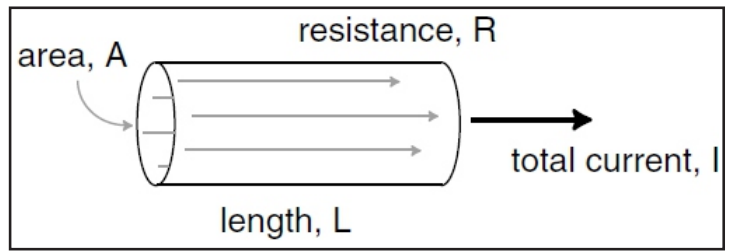

Gambar 4. Ilustrasi aliran arus listrik yang mengalir melewati medium berbentuk silinder (Everett, 2013).

Lowrie (2007) menyatakan bahwa berdasarkan Hukum Ohm, besar resistivitas medium $\rho$ (Ohmmeter) dapat diidentifikasi dengan mengetahui beda potensial antara ujung-ujung silinder $V$ (Volt), arus listrik yang mengalir melalui medium $I$ (Ampere), luas penampang medium $A$ 
(meter kubik), dan panjang medium $L$ (meter), seperti pada persamaan (1) berikut:

$\rho=R \frac{A}{L}$

Dengan resistensi $R(\mathrm{Ohm})$ seperti pada persamaan (2) berikut :

$$
R=\frac{V}{I}
$$

Pengukuran resistivitas pada penelitian ini dilakukan secara mapping, yaitu penyelidikan sebaran resistivitas bawah permukaan secara lateral (horizontal) dengan konfigurasi dipol-dipol seperti pada Gambar 5. Adapun alat geolistrik yang digunakan yaitu Resistivitymeter merk Oyo. Elektroda terdiri dari dua buah elektroda arus dan dua buah elektroda potensial dengan spasi $a$ sejauh 10 meter. Kemudian kedua pasang elektroda arus dan potensial tersebut ditancapkan dengan jarak $n a$ dengan $\mathrm{n}$ adalah faktor rasio (pada penelitian ini diaplikasikan $1 \leq n \leq 6$ ).

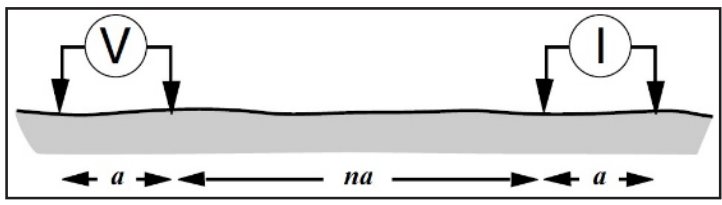

Gambar 5. Posisi elektroda arus dan potensial pada konfigurasi dipol-dipol (Milson, 2003).

Nilai resistivitas yang diperoleh dari pembacaan nilai potensial di permukaan dengan asumsi medium tersebut homogen yaitu resistivitas semu. Resistivitas semu $\rho_{a}$ (Ohm meter) dapat dirumuskan sebagai:

$\rho_{a}=\kappa \frac{V}{I}$

Dengan $\kappa$ adalah faktor geometri (meter) yang ditentukan oleh susunan elektroda arus dan potensial (Telford drr., 1990). Pada konfiguasi dipol-dipol, faktor geometri dapat dirumuskan sebagai berikut:
$K=n(n+1)(n+2) \pi a$

Pada pengukuran resistivitas, variasi konfigurasi elektroda akan menunjukkan nilai resistivitas yang sama jika diaplikasikan pada medium bawah permukaan yang sama. Nilai resistivitas ini yang disebut resistivitas sebenarnya (true resistivity).

\section{HASIL DAN PEMBAHASAN}

Hasil penelitian pada lokasi pertama ditunjukkan pada Gambar 6. Nilai resistivitas material longsor berupa lapisan lapuk lebih besar dibandingkan nilai resistivitas bidang gelincir. Nilai resistivitas lapisan lapuk sebesar 70,59 $-515,75 \Omega \mathrm{m}$ diinterpretasi berupa tanah penutup dan pasir lempungan dengan ketebalan 4,5 - 15,0 meter. Adapun nilai resistivitas bidang gelincir sebesar 2,93 - 47,43 $\Omega \mathrm{m}$ diinterpretasi berupa lapisan lempung dengan bidang yang berbentuk relatif rata (bergelombang landai). Interpretasi ini mengacu pada Tabel 1 dan penelitian sebelumnya yang telah mengidentifikasi litologi bawah permukaan di lokasi penelitian berdasarkan sebaran resistivitas secara sounding (Muhardi dan Wahyudi, 2019).

Hasil penelitian pada lokasi kedua ditunjukkan pada Gambar 7. Nilai resistivitas material longsor berupa lapisan lapuk lebih besar dibandingkan nilai resistivitas bidang gelincir. Nilai resistivitas lapisan lapuk sebesar 21,41 $-70,59 \Omega$ m diinterpretasi berupa tanah penutup dan pasir lempungan dengan ketebalan 1,5 - 7,0 meter. Adapun nilai resistivitas bidang gelincir sebesar 1,32 - 14,38 $\Omega \mathrm{m}$ diinterpretasi berupa lempung dengan bidang yang berbentuk relatif rata (bergelombang landai).

Hasil interpretasi dari nilai resistivitas yang diperoleh pada lapisan yang berperan sebagai bidang gelincir adalah lapisan yang banyak mengandung mineral lempung dengan nilai resistivitas yang relatif rendah jika dibandingkan dengan lapisan lapuk (Muhardi drr., 2019). Singkapan bidang gelincir berupa lempung pada 


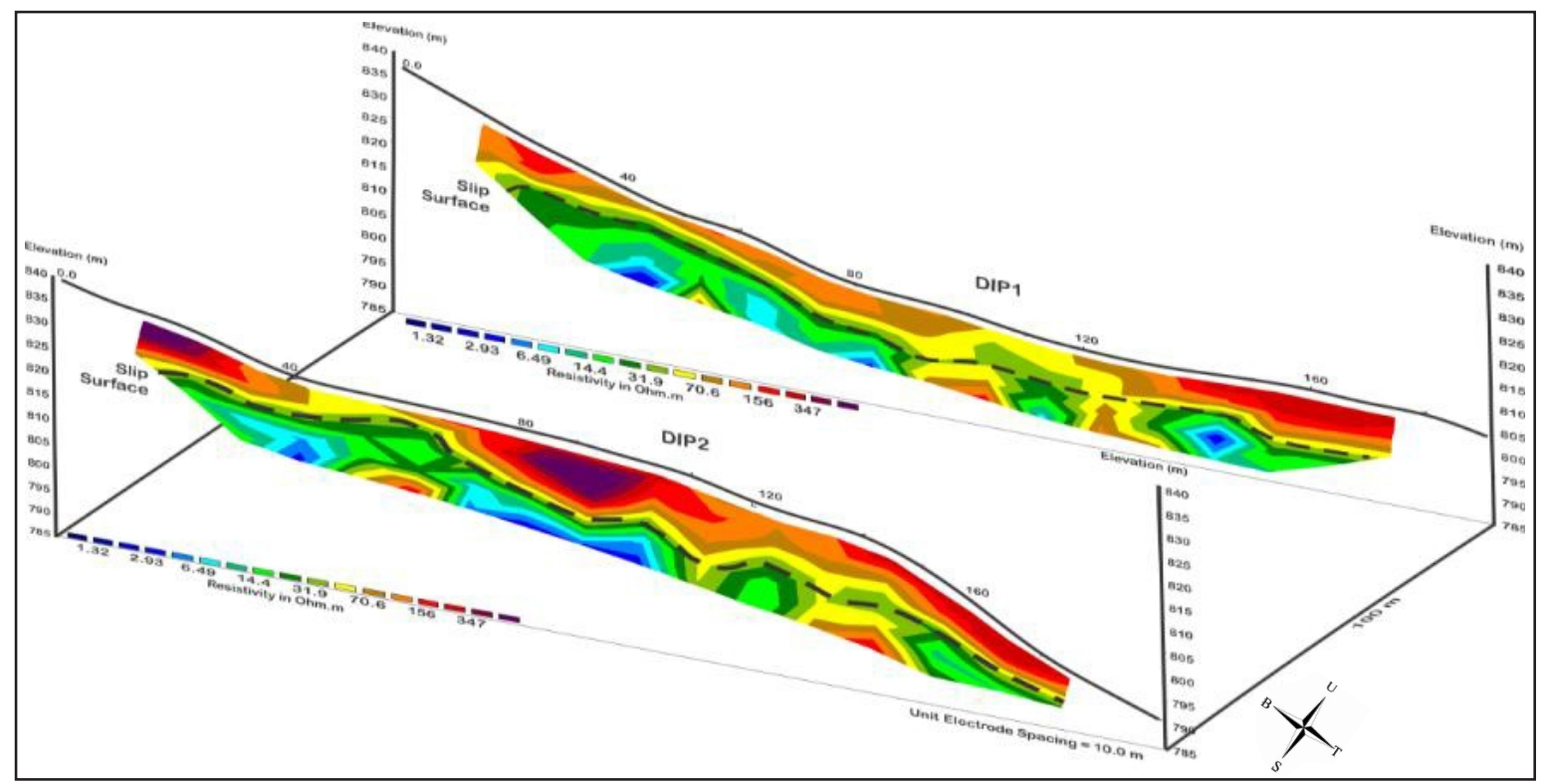

Gambar 6. Penampang pseudosection resistivitas 2D pada lokasi pertama (lintasan 1 dan 2).

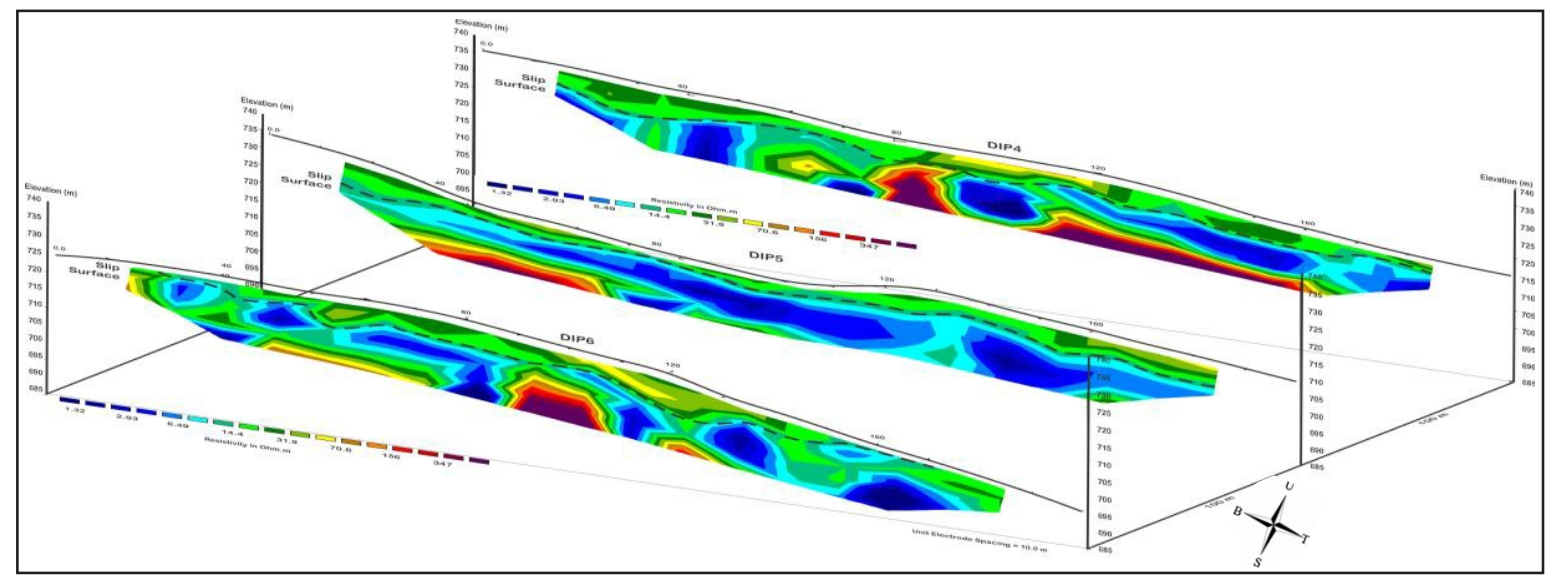

Gambar 7. Penampang pseudosection resistivitas 2D pada lokasi kedua (lintasan 3, 4, dan 5).

daerah penelitian ditemukan pada area longsor di lokasi pertama dan area yang mengalami erosi pada lokasi kedua, seperti pada Gambar 8 .

Lapisan yang mengandung mineral lempung umumnya mempunyai nilai resistivitas yang relatif lebih rendah. Hal ini disebabkan karena duafaktor, yaitu adanya kandungan ion negatif dan polarisasi membran (Milson, 2003). Mineral lempung mempunyai muatan listrik negatif, yang disebabkan oleh pengaruh dari interaksi antar ion penyusun mineral lempung. Interaksi antar ion ini menyebabkan terjadinya polarisasi. Polarisasi membran merupakan akumulasi ion pada mineral lempung karena disebabkan oleh adanya medan listrik. Ukuran butiran mineral lempung yang sangat halus dan mempunyai muatan listrik akan menarik sekaligus menjebak ion-ion pada saat terdapat medan listrik (Telford drr., 1990). Akumulasi ion yang terjebak akan menyebabkan bertambahnya muatan listrik pada mineral lempung sehingga tegangan dari medan listrik menjadi berkurang. Dengan demikian, jika tegangan berkurang, maka nilai resistivitas secara otomatis akan menjadi kecil.

Bidang gelincir berupa lempung yang dikenal licin jika terkena air, dan diduga terbentuk dari melapuknya batuan dasar di lokasi penelitian yang tersusun atas breksi vulkanik dan batupasir 


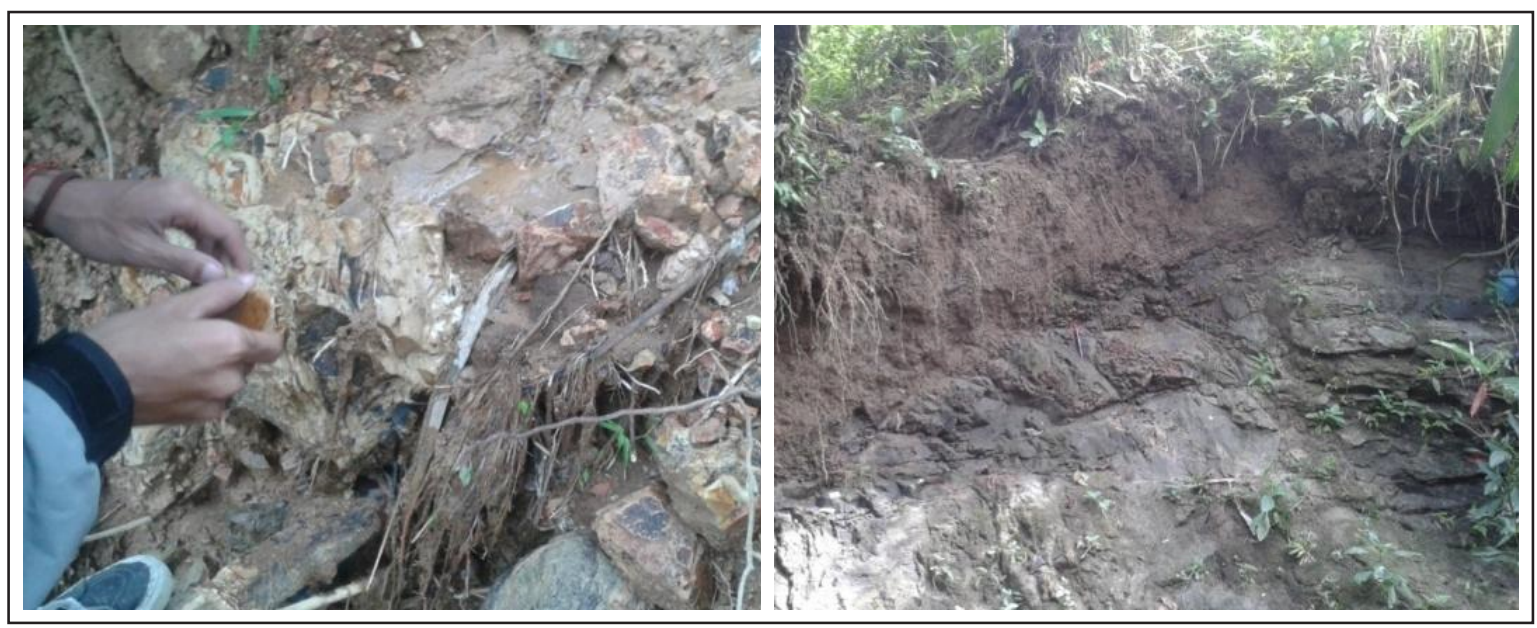

Gambar 8. Bidang gelincir berupa lempung; a) lokasi pertama, dan b) lokasi kedua.

tufan, breksi bersusunan andesit yang mengandung urat-urat kalsit (Condon drr., 1996). Keberadaan mineral lempung pada bidang gelincir dihasilkan dari proses alterasi yang disebabkan karena adanya pengaruh magma panas secara terus-menerus dalam jangka waktu yang cukup lama. Sumber panas yang berasal dari magma tersebut dapat meresapkan hidrotermal ke dalam lapisan batuan di sekelilingnya. Kinasti (2014) telah mengidentifikasi jejak magma tersebut di Desa Watumalang dan Desa Windusari Kecamatan Pagentan Kecamatan Banjarnegara yang berjarak \pm 4 kilometer sebelah utara- timur laut dari Desa Clapar sebagai batuan beku terobosan (intrusi).

Lapisan lapuk yang menjadi material longsor berupa tanah penutup dan pasir lempungan merupakan material yang tidak terkonsolidasi dengan kuat, memiliki pori yang cukup banyak antar butirannya. Lapisan lapuk merupakan hasil dari hancuran struktur batuan dasar (bedrock) pada zona pelapukan. Material ini umumnya akan menyerap dan menyimpan air sehingga akan memperlemah ikatan antar partikel tanah dan menambah beban pada lapisan lapuk tersebut. Pada kondisi jenuh, ikatan antar partikel tanah ini akan mudah terlepas sehingga menyebabkan terjadinya longsor. Hal ini disebabkan lapisan lapuk ini tidak kompak sehingga akan mudah mengalami longsor jika mengalami infiltrasi air.
Hasil penelitian menunjukkan bahwa ketebalan lapisan lapuk pada lokasi pertama (Gambar 9a) lebih besar dibandingkan pada lokasi kedua (Gambar 9b). Ketebalan lapisan lapuk pada lokasi pertama mencapai 4,5 - 15,0 meter (hasil ini dikonfirmasi dengan longsor yang terjadi pada Maret 2017), sedangkan pada lokasi kedua mencapai 1,5 - 7,0 meter. Hal ini dipengaruhi oleh kemiringan lereng pada lokasi pertama lebih besar dibanding lokasi kedua. Pada kemiringan yang kecil, lapisan lapuk akan mudah mengendap dan terkonsolidasi sehingga partikel-partikel tanah penyusunnya menjadi lebih padat (solid) dan kompak dibandingkan pada lokasi pertama yang memiliki kemiringan lereng yang lebih besar, hal ini sesuai dengan pengamatan di lapangan dan nilai resistivitas yang diperoleh pada kedua lokasi tersebut.

Ketebalan lapisan lapuk menentukan dimensi material longsor yang akan terlepas. Bersama dengan gaya gravitasi, ketebalan lapisan lapuk akan mempengaruhi gaya berat material longsor, sehingga akan berdampak pada kecepatan pergerakan longsor yang meluncur di atas permukaan bidang gelincir.

Tipe longsor pada lokasi pertama umumnya sama dengan lokasi kedua, hal ini disebabkan permukaan bidang gelincir umumnya berbentuk lurus (tidak melengkung), sehingga memungkinkan terjadi gerakan material longsor dengan mekanisme luncuran (slides) secara 


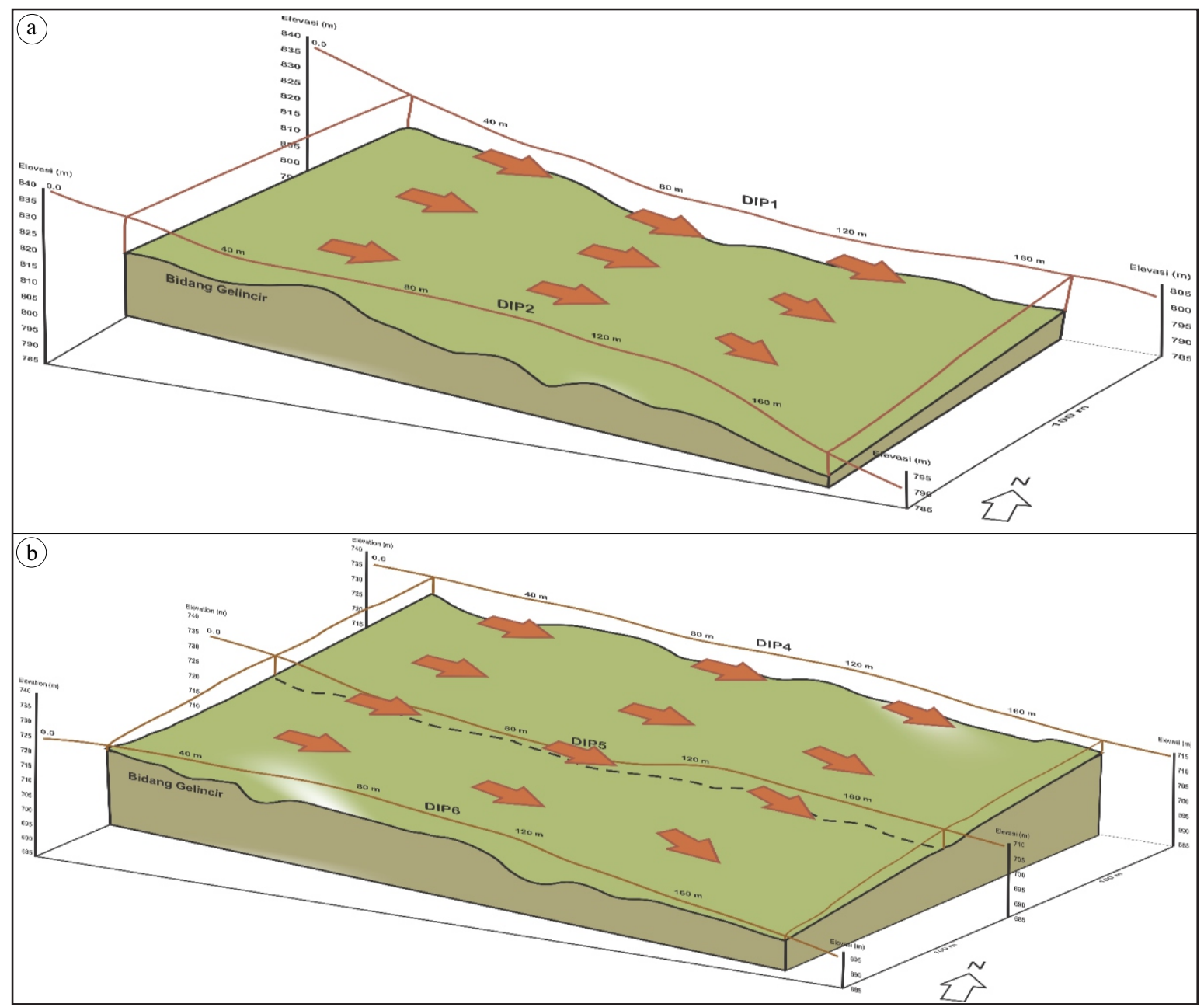

Gambar 9. Ilustrasi tipe longsor translasi pada lokasi: a) pertama; b) kedua.

translasi. Gambar 8 dan 9a, b merupakan ilustrasi yang dibuat untuk menggambarkan pergerakan longsor pada lokasi pertama dan kedua.

\section{KESIMPULAN}

Penelitian ini menunjukkan bahwa bidang gelincir pada lokasi pertama mempunyai nilai resistivitas sebesar 2,93 - 47,43 $\Omega \mathrm{m}$ berupa lapisan lempung dengan bidang berbentuk relatif rata pada kedalaman 4,5 - 15,0 meter. Adapun pada lokasi kedua bidang gelincir mempunyai nilai resistivitas sebesar 1,32 - 14,38 $\Omega \mathrm{m}$ berupa lapisan lempung dengan bidang berbentuk relatif rata pada kedalaman 1,5 - 7,0 meter. Berdasarkan bentuk bidang gelincir yang diidentifikasi pada lokasi pertama dan kedua, tipe longsor di Desa Clapar diprediksi berupa longsor translasi.

\section{UCAPAN TERIMA KASIH}

Kami ucapkan terima kasih kepada masyarakat dan pemerintah Desa Clapar yang telah memfasilitasi dan memberikan dukungan sehingga penelitian ini dapat terlaksana dengan baik.

\section{DAFTAR PUSTAKA}

Bell, R., Kruse, J.E., Garcia, A., Glade, T., Bonn, Hordt, A. dan Braunschweig, 2006. Subsurface Investigations of Landslides using Geophysical Methods Geoelectrical Applications in the Swabian Alb (Germany). Geographica Helvetica, Vol. 61, No.3: 201-208.

Condon, W. H., Pardyanto, L., Ketner, K. B., Amin, T. C., Gafoer, S. dan Samodra, H., 1996.Peta Geologi Lembar Banjarnegara dan Pekalongan, Jawa,1:100.000,Pusat 
Penelitian dan Pengembangan Geologi, Bandung.

Everett, M.E. 2013. Near Surface Applied Geophysics. Cambridge University Press, New York.

Hardiatmo, H.C., 2012. Tanah Longsor dan Erosi, Kejadian dan Penanganan. Gadjah Mada University Press, Yogyakarta.

Hidayat, R. dan Munir, M.D., 2019.Longsor di Sungai Cipunagara dan Desain Penanganannya. Jurnal Lingkungan dan Bencana Geologi, Vol. 10, No.1: 19-27.

Highland, L. dan Bobrowsky, P. 2008. The Landslide Handbook - A Guide to Understanding Landslides. US Geological Survey, Virginia.

Kinasti, R.R.M.A., 2014. Pengaruh Struktur Geologi terhadap Gerakan Tanah di Dusun Windusari, Desa Metawana, Kecamatan Pagentan, Kabupaten Banjarnegara, Propinsi Jawa Tengah, Jurnal Ilmiah MTG, Vol.7, No.1: 1-14

Ling, C., Xu, Q., Zhang, Q., Ran, J., dan Lv, H., 2016.Application of Electrical Resistivity Tomography for Investigating the Internal Structure of a Translational Landslide and Characterizing its Groundwater Circulation (Kualiangzi Landslide, Southwest China). Journal of Applied Geophysics, Vol.131: 154-162.

Lowrie, W., 2007.Fundamentals of Geophysics, Second Edition. Cambridge University Press, New York.

Marwanta, B., 2017. Analisis Data Resistivity untuk Menentukan Potensi Bencana Tanah Longsor di Kampung Legok Hayam, Desa Girimekar, Kecamatan Cilengkrang, Kabupaten Bandung. Jurnal Alami, Vol.1, No.1: 11-16.

Milson, J., 2003.Field Geophysics, Third Edition. Jhon Willey and Sons Ltd, England.

Muhardi dan Wahyudi, 2019. Identifikasi Li- tologi Area Rawan Longsor di Desa ClaparBanjarnegara Menggunakan Metode Geolistrik Resistivitas Konfigurasi Schlumberger. Jurnal Fisika, Vol.9, No.2: 52-59.

Muhardi, Perdhana, R. dan Nasharuddin, 2019. Identifikasi Keberadaan Air Tanah Menggunakan Metode Geolistrik Resistivitas Konfigurasi Schlumberger (Studi Kasus: Desa Clapar Kabupaten Banjarnegara). Prisma Fisika, Vol.7, No.3: 331-336.

Permata, A., Juniansyah, A., Nurcahyati, E., Afrizal, M.D., Untoro, M.A.S., Arifatha, N, Adiwijaya, R.R.Y., Widartono, B.S., dan Purwanto, T.H., 2016. Aerial Photographs of Landslide on Clapar, Madukara District of Banjarnegara as a Spatial Geodatabase.IOP Conference Series: Earth and Environmental Science.

Paripurno, E. T., Hartadi, J., Raharjo, S., dan Alfiani, O., 2019. Mass Movement Disaster Risk Mitigation in Clapar District and Surrounding Area, Banjarnegara Regency, Central Java.IOP Conference Series: Earth and Environmental Science.

Reynolds, J.M., 1997. An Introduction to Applied and Environmental Geophysics.John Wiley and Sons Ltd,England.

Sidle, R.C. dan Ochiai, H., 2006. Landslides: Processes, Prediction and Land Use, American Geophysical Union, Washington DC.

Sutasoma, M., Susilo, A., dan Suryo, E.A., 2017. Penyelidikan Zona Longsor dengan Metode Resistivitas dan Analisis Stabilitas Lereng untuk Mitigasi Bencana Tanah Longsor (Studi Kasus di Dusun Jawar, Desa Sri Mulyo, Kecamatan Dampit, Kabupaten Malang, Provinsi Jawa Timur). Indonesian Journal of Applied Physics, Vol. 7, No.1: 36-45.

Telford, W. M., Geldart, L.P. dan Sheriff, R.E., 1990. Applied Geophysics, Second Edition. Cambridge University Press, New York. 